\title{
Letters
}

Website: www.bmj.com

Email: letters@bmj.com

\section{Research assessment exercise}

\section{Single funding structure should be created for teaching hospitals}

EDITOR-Williams has summarised the dangers and deficiencies of the research assessment exercise. ${ }^{1}$ The inevitable and desired consequence of the exercise was to concentrate resources in a limited number of institutions, and in this the process has been a success. Resources have been increasingly directed towards a limited and predictable number of institutions, generally to the detriment of the provincial medical schools, which have been left dangerously exposed both in matters of staff recruitment and in funding.

Medical schools are supposed to be responsible for training doctors and the provision of clinical services, as well as undertaking research. The clear message from the research assessment exercise, however, is that the first two functions are of minor importance, because the funding is not affected by either dedication to patient care or the quality and effort put into teaching. Furthermore, many of the provincial schools have survived and prospered in the past by the virement of NHS funding into academic posts. This process is now under threat as academic staff are drawn back from clinical work and as posts funded by the Higher Education Funding Council for England are predominantly directed towards research and away from clinical work. The interaction between NHS and academic staff in teaching hospitals should be seamless and complementary. The reality is that the relationship is being torn apart, with little prospect for the development of posts that will not improve the results of the research assessment exercise, even if the benefits to the profile and quality of staff in some of the "Cinderella" disciplines may be substantial.

Is it not time to re-examine the existing structure and to recognise that the provincial medical schools can never compete in the research assessment exercise without grossly distorting their function? There is a strong case to have a single funding structure for teaching hospitals and to create separate universities of health sciences, in which a balance could be achieved between teaching, clinical service, and research. All staff would be academic and service oriented, with the capacity to recognise particular talents within the structure. Universities of health sciences would include all disciplines related to patient care.
A change in the structure and management of teaching hospitals was recently viewed favourably in a report by a select committee of the House of Lords. ${ }^{2}$ Williams described the research assessment exercise as a "dysfunctional juggernaut," but if it is to continue then new structures must be initiated to safeguard the integrity and quality of medical training in the United Kingdom.

E Malcolm Symonds Former member of panel for hospital based medicine

Nursery Cottage, The Green, Care Colston,

Nottinghamshire NG13 8JE

1 Williams G. Misleading, unscientific, and unjust: the United Kingdom's research assessment exercise. BMJ 1998;316 1079-82. (4 April.)

2 House of Lords Select Committee on Science and Technology. Clinical academic careers: report with evidence. London: HMSO, 1997. (3rd report on science and technology.)

\section{Some of author's suggestions were} misleading

EDITOR-Williams suggests that the research assessment exercise "recognises only those individuals funded by the Higher Education Funding Councils." This is misleading. The 1996 guidance on submissions for the exercise states (clause 21): "staff eligible to be included ... are those who have ... a contract with the institution requiring them to undertake academic duties (including teaching, research or both) and who receive ... a salary from it however funded." What determines inclusion is being on the payroll of the institution, not the source of the funding. The guidance expressly indicates that this may include NHS "A + B" staff (those with joint appointments between the NHS and a university).

Williams also suggests that researchers supported by short term external contracts are excluded. The research grants from which these researchers' salaries are funded and the number of these researchers supervised by academic staff are included, and both influence the ratings. It may be argued that to include them in calculating the volume of research would be a form of double counting. There are exceptions. Principal investigators (typically research fellows-defined for the purposes of the research assessment exercise as individuals who hold specific awards on the basis of their own research record or research proposals, such as Medical Research Council or Wellcome fellows) may be included if employed and paid by the institution.
Williams eschews reliance on levels of grant income, arguing that this is no guarantee of the quality of research produced. If a $£ 150000$ grant is not a reliable indicator of a better research outcome than one of $£ 50000$, surely the same holds true for the larger number of researchers employed on the more generously funded study.

Williams argues that quality of research output should be assessed by journal of publication with ratings determined by assessment panels and should be published before each research assessment exercise "to democratise the scoring process." They would be scored simply by multiplying the number of publications by the journal's numerical rating. This ignores the behavioural consequences of such a system once established. Most researchers would concentrate their submissions on top rated journals, creating log jams. Time taken to review submissions and time between acceptance and publication would quickly lengthen, slowing up dissemination and distorting the research assessment exercise further. Those who anticipate such developments and submit their papers to journals rated 3 or 4 might well accumulate higher scores than those who submit papers ultimately accepted by journals rated 5 .

Nevertheless, Williams makes several valid criticisms. The research assessment exercise remains far from perfect but improvement remains elusive.

Mike Holmes Director

Nigel Oswald Professor of primary care

School of Health, University of Teesside,

Middlesbrough TS1 3BA

1 Williams G. Misleading, unscientific, and unjust: the United Kingdom's research assessment exercise. BMJ 1998;316: 1079-82. (4 April)

2 Higher Education Funding Councils. 1996 Research assessment exercise: guidance on submissions. Bristol: HEFC, 1995.

\section{Departments do not know rules of} exercise

EDIToR-Williams attacked the United Kingdom's research assessment exercise as misleading, unscientific, and unjust. ${ }^{1} \mathrm{He}$ did not mention one of its most unjust aspects: that submissions have to be prepared for a game in which the rules are unknown.

Firstly, the published rules are unworkable. In a submission, research is divided into subareas of activity, to be decided by the department concerned. Each of the four publications submitted by a "research active" member of staff is assigned to a subarea of activity. The panel then grades each subarea as being of "international excellence," "national excellence," or "not excellent." The other information available to the panel is 
not linked to subarea of activity-for example, grant funding is not classified by subarea so cannot be used if the published rules are followed.

Secondly, panels invent their own rules. One panel member told me that to get a grade 5 or $5^{*}$ a department had to have a Medical Research Council programme grant. The only place where this information can be given is in the very brief free text, so the author of the submission has to know that this is what the panel wants. The definition of excellence also varies. The biochemistry panel gave 12 of 18 submissions grade $5^{*}$ or 5-"attainable levels of international excellence in some subareas of activity and attainable levels of national excellence in virtually all others." Thus this panel thinks that two thirds of departments surpass all others in virtually all areas. In comparison, the community based clinical subjects panel gave only $18 \%$ of submissions grade 5 or $5 *$. This results in a transfer of funds from medicine to other subjects.

Thirdly, only a small part of researchers' output can be submitted-just four publications from four years' work. As we do not know how this information is to be used the choice is difficult. Should we cite research carried out with members of other institutions, which must be indicated as such in the submission? We don't know whether collaboration is considered good (cross fertilisation of ideas, economies of scale) or bad (partially the work of others).

Guessing and game playing invalidate the whole research assessment exercise. As Williams advocates, total published research output is the only valid information for research assessment. Departments would not then have to guess what panels have in mind, and special knowledge of the inner workings of the system would be unimportant.

J Martin Bland Professor of medical statistics St George's Hospital Medical School, London SW17 0RE

1 Williams G. Misleading, unscientific, and unjust: the United Kingdom's research assessment exercise. BMJ 1998;316: 1079-82. (4 April.)

\section{Exercise has implications for clinical} academic medicine

EDITOR-We agree with the criticism levelled at the research assessment exercise by Williams and with many of his recommendations for improvements to the system. ${ }^{1}$ One area that he did not cover, however, was the impact of the exercise on junior clinical academics.

Clinical lectureships are generally held by clinicians at the specialist registrar grade. They serve two functions, allowing the lecturers to complete higher specialist training in their chosen clinical specialty (which takes up over half of their time) and to obtain a training in research. While an appointee to a non-clinical lectureship might be expected to have several years' postdoctoral experience, clinical lecturers often have little previous research experience, and many do not possess higher degrees.
Given this lack of experience and available research time, clinical lecturers seem to be unattractive in terms of the research assessment exercise. They will often struggle to produce four peer reviewed publications, let alone bring in appreciable grant income. At best, this can lead to a desire to appoint more experienced clinicians-for example, those who have completed higher specialist training-with the result that those interested in clinical academic careers are faced with a prohibitively long training. At worst, universities are tempted not to appoint people to the clinical lecturer grade and to convert these posts to non-clinical lectureships.

We support Williams's suggestion that a group's total research output should be assessed, rather than that of only some individuals. This would at least dilute the extent to which clinical lecturers can be seen as liabilities in terms of the research assessment exercise. We believe, however, that further action is needed and that universities should be positively encouraged to appoint clinical lecturers and to support them fully. If this is not done then the future for clinical academic medicine in this country is bleak.

R H McAllister-Williams Clinical lecturer A H Young Senior lecturer

Department of Psychiatry, University of Newcastle upon Tyne, Royal Victoria Infirmary, Newcastle upon Tyne NE1 4LP

1 Williams G. Misleading, unscientific, and unjust: the United Kingdom's research assessment exercise. BMJ 1998;316: 1079-82. (4 April.)

\section{Concealed breast cancer causes delayed treatment}

EDITOR-Nosarti et al suggested that delay by patients accounts for a large part of the time till treatment for breast cancer is started. ${ }^{1}$ We agree that this delay is an important problem; it is not often analysed as policies are targeted at earlier treatment of small lesions. Iversen et al considered a delay of eight weeks by patients to be a challenge to health services.

We investigated the incidence of concealed breast cancer at Hartlepool General Hospital between January 1988 and December 1992 and are following up patients for five years after the initial diagnosis. We defined a breast carcinoma as a concealed cancer when the patient had been aware of a breast lump for six months or more before seeking medical advice. We retrospectively identified all patients with breast cancer through pathology records. Forty eight of the 170 patients with newly diagnosed disease had concealed carcinomas (mean (SE) time of concealment 24.3 (2.7) months). This number includes patients with other diagnoses who admitted to the lump only after it had been found by a doctor.

The median age of patients presenting in this way was 69 years and 8 months. Seven patients were under 50 . Two were lactating when they found the lump. Thirty two patients were aged over 65 , indicating that the problem of concealment is larger in older women. Sixteen had fungating or ulcerated lesions at presentation. One patient died of carcinomatosis on the day after presentation; four others survived less than six months. Five patients (excluding those with carcinomatosis who were receiving palliative care) either refused all specific treatment or did not turn up for appointments for treatment.

Breast screening began in this region in April 1990, just over half way through this study. Patients with breast cancer detected on screening were not treated at this hospital and were not included in this analysis. Although screening would not be expected to alter the course of these late tumours, the public education that accompanies the programme should increase awareness of breast disease. The proportion of patients presenting with concealed tumours before and after the initiation of screening did not differ significantly (24 out of 91 patients before screening, 24 out of 79 after screening).

Awareness of breast carcinoma has increased with extensive media coverage, but a substantial proportion of women still do not seek early consultation. Further emphasis is needed to encourage all women with symptoms to seek appropriate advice.

Rosina Ahmed Specialist registrar General Surgery, K Floor, Royal Hallamshire Hospital, Sheffield S10 2JF

G R McLatchie Professor of surgical science University of Sunderland, Hartlepool General Hospital, Hartlepool TS24 9AH

1 Nosarti C, David A, Crayford T, Elias E, Roberts J. Delayed diagnosis for breast disease is mostly due to patients. BMJ 1997;315:1021. (18 October.)

2 Iversen JR, Amlie E, Hagen S, Harbitz T, Karesen R, Ro J. Late diagnosis of advanced breast cancer-a challenge for health services. Tidsskr Nor Laegeforen 1992;112:1821-4.

\section{Methadone treatment is widely accepted in prisons in New South Wales}

EDIToR-The study by Seaman et al provides the first confirmation of what many have observed for years - that there is strong evidence that appropriate treatment for drug misuse should be made available to all prisoners, especially before release. ${ }^{1}$ It is normal practice (and a requirement under international treaties) to provide medical treatment for prisoners that is similar to that which they would receive in the community. Methadone and other treatments for drug dependence should be no different. We know that there are illicit drugs in most prisons. Additionally, the prevalence of infection with HIV and hepatitis B and C is higher in prisoners than in the general population, and risk taking behaviour is widespread.

Methadone treatment was introduced into prisons in New South Wales in 1987 as a pre-release measure. Treatment has since been expanded to become more widely available for voluntary maintenance. Despite some initial misgivings, there has been almost universal acceptance of this treatment by prisoners, staff, and medical 
authorities. It has been associated with reduced injecting in prisons, ${ }^{2}$ and is currently being studied in relation to the transmission of bloodborne viral infections.

Andrew Byrne General practitioner

75 Redfern St, Redfern, 2016 NSW, Australia

Kate Dolan Senior research fellow

National Drug and Alcohol Research Centre, University of New South Wales, Sydney, 2033 NSW, Australia

1 Seaman SR, Brettle RP, Gore SM. Mortality from overdose among injecting drug users recently released from prison: database linkage study. BMJ 1998;316:426-8. (7 February.) 2 Dolan K, Hall W, Wodak A. Methadone maintenance reduces injecting in prison. $B M J$ 1996;312:1162.

\section{Measles, measles vaccination, and Crohn's disease}

\section{Second immunisation has not affected incidence in England}

EDITOR-Metcalf concludes that the scientific evidence does not support a causal link between measles virus and Crohn's disease. ${ }^{1}$ Though few readers of the $B M J$ are likely to disagree with her appraisal of the science, parental concern about the safety of the vaccine remains high fuelled by continuing media interest in this controversial topic. More worrying is the recent decline in MMR vaccine coverage ${ }^{2}$ and evidence which suggests that most practice nurses would not give their own child a second dose of MMR vaccine because of concerns about vaccine safety. ${ }^{3}$

One of the claims made by the leading proponent of the hypothesis that measles vaccine causes Crohn's disease is that there has been a "dramatic escalation" in paediatric cases in the wake of the 1994 national measles-rubella vaccination campaign targeted at school aged children. ${ }^{4}$ We have monitored hospital discharge diagnoses for Crohn's disease (ICD-9 code 555 until March 1995, ICD-10 code K55 from April 1995) in children aged 5-16 years before and after the campaign using computerised hospital episode statistics from all districts in England (figure). Children with new cases of

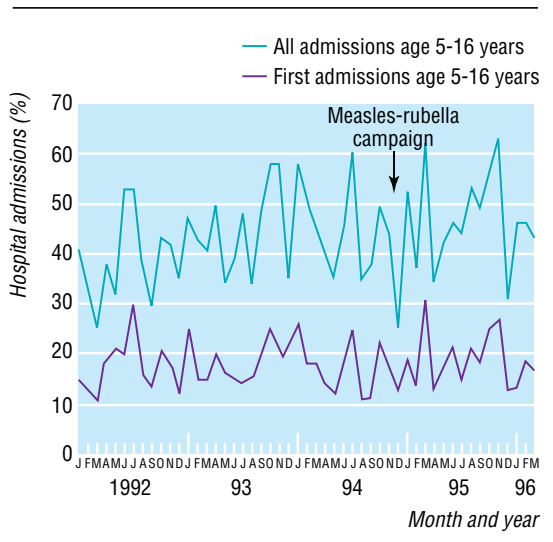

Hospital admissions for Crohn's disease, January 1992 to March 1996
Crohn's disease are almost always admitted to hospital, and this is a well established method of monitoring trends in incidence of the disease. Repeat admissions in the same child were identified by matching sex, date of birth, and postcode.

No increase was evident in either first admissions or all admissions for Crohn's disease since the campaign. Although the latent period between exposure to measlesrubella vaccine and alleged onset of Crohn's disease was not stated by Wakefield, our data exclude an effect within the first 16 months. This technique can be reapplied annually, allowing the cohort immunised in the 1994 campaign to be followed longer term.

We are not aware of any published evidence to support the hypothesis that re-exposure to measles vaccine can provoke the onset of Crohn's disease. However, evidence which counters unsubstantiated allegations may help health professionals reassure themselves, as well as concerned parents, about the safety of measles vaccine given as a second dose in combination with another live viral vaccine.

Elizabeth Miller Head of immunisation division Pauline Waight Principal scientist

Public Health Laboratory Service Communicable Disease Surveillance Centre, London NW9 5EQ

1 Metcalf J. Is measles infection associated with Crohn' disease? BMJ 1998;316:166. (17 January.)

2 Begg N, Ramsay M, White J, Bozoky Z. Media dents confidence in MMR vaccine. BMJ 1998;316:561.

Roberts N. Why are practice nurses scared of MMR2? GP Medicine January 231998.

4 Wakefield AJ. National Vaccine Information Centre's first international public conference on vaccination, Alexandria, VA, September 13-15 1997. Vienna: VIC, 1997.

\section{Crohn's disease has not increased in Finland}

EDITOR-We believe Finnish data can add to the discussion about exposure to wild measles virus or MMR vaccine and subsequent development of Crohn's disease. ${ }^{1}$ Finland has had a national register of those prescribed long term treatment for Crohn's disease since 1986 . We used the register to obtain the annual number of incident Crohn's cases from 1986-92 in those aged $0-14$ and 15 -24 years.

Transmission of wild measles virus was still occurring in Finland in the 1970s despite $70 \%$ coverage with monovalent Schwarz vaccine since 1975. In 1982, a two dose MMR vaccination programme was launched for 14-18 month and 6 year old children; coverage for the two doses was over $90 \%,{ }^{2}$ and wild virus was eradicated. ${ }^{3}$ In 1992 we randomly sampled 453 children from the National Population Register who had remained healthy during the last measles outbreak in Finland in 1988. Vaccination status and measles history were determined from the child's home or health care centre vaccination card (unpublished data). We calculated the proportion of each annual birth cohort for 1967-87 who received 0 , one, two, and three doses of measles vaccine (some received one dose of Schwarz and two doses of MMR vaccine) or had wild measles infection regardless of vaccination status.

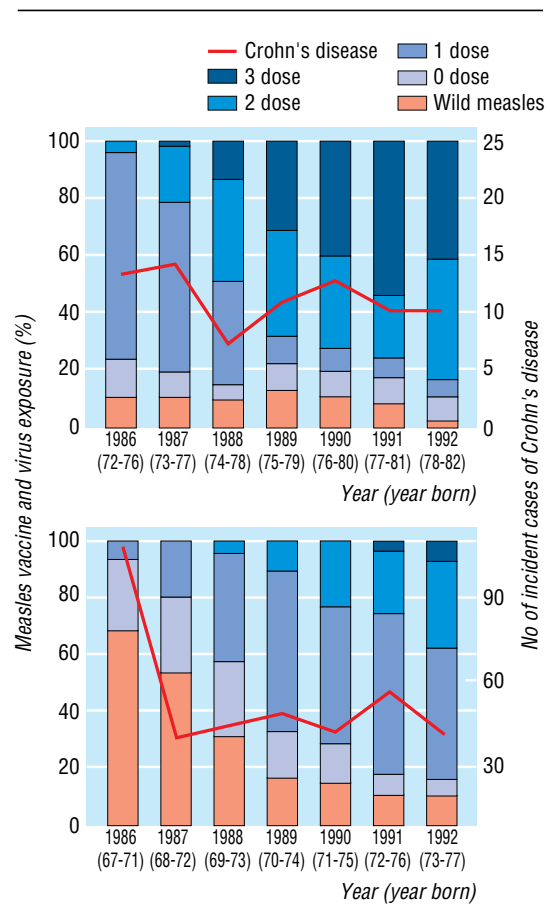

Annual incident cases of Crohn's disease and lifetime measles vaccination and wild measles virus exposure in 10-14 and 15-19 year olds in Finland, 1986-92

From 1986 to 1992 the proportion of 15-19 year olds infected by wild virus fell sharply (figure), with a significant increase in the proportion receiving one or more doses of measles vaccine. Over the same period the proportion of 10-14 year olds receiving two or more doses of MMR vaccine increased. Few 10-14 year olds have had measles.

The annual number of incident cases of Crohn's disease for 15 to 24 year olds fell the year after the registry was started. This is probably due to inclusion of previously diagnosed cases. The annual number of cases has since remained stable for both age groups $(8 / 100000 /$ year for 15 -24 year olds and $1 / 100000 /$ year for $0-14$ year olds).

Over the 10 years widespread exposure to wild virus at 1-9 years of age has changed to multiple doses of live attenuated vaccine starting at 14 months of age. However there has been no difference in the incidence of Crohn's disease after follow up for up to 19 years. Although these data do not exclude a possible association between wild measles virus and Crohn's disease, if early exposure to MMR vaccine increased the risk we would expect an increasing incidence of Crohn's disease in Finland in these age groups.

R G Pebody Fellow

European Programme of Intervention Epidemiology Training, Helsinki, Finland

M Paunio Senior researcher

University of Helsinki, Department of Public Health, Helsinki, Finland

P Ruutu Chief of Infectious Disease Surveillance Unit Department of Infectious Disease Epidemiology, National Public Health Institute, Helsinki, Finland

1 Metcalf J. Is measles infection associated with Crohn's disease? BMJ 1998;316:166. (17 January.) 
2 Peltola H, Heinonen O, Valle M, Virtanen M, Karanko V, Cantell K. The elimination of indigenous measles, mumps and rubella from Finland by a 12 year, two dose vaccination programme. $N$ Engl J Med 1994;331:1397-402 3 Peltola H. Davidkin I, Valle M, Paunio M, Hovi T. Heinonen O, et al. No measles in Finland. Lancet 1997;350:1364-5.

\section{Age specific prevalences do not suggest} association with in utero exposure

EDITOR-Before immunisation was introduced in 1963 there was a regular pattern of measles epidemics every two years in England and Wales. If the proposed association between exposure to measles in utero and subsequent development of Crohn's disease ${ }^{1}$ truly exists then it would be expected that babies born in the year of a measles epidemic would have a higher risk of subsequently developing Crohn's disease. Consequently the age specific prevalence of Crohn's disease should vary from year to year.

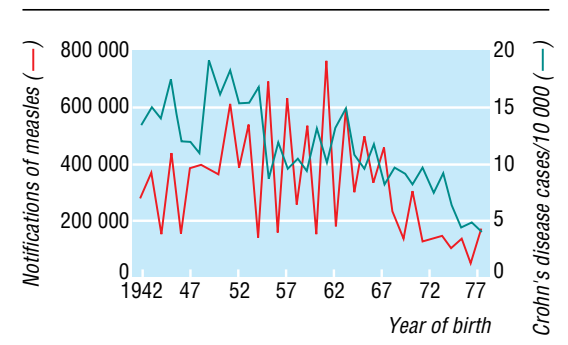

Prevalence of Crohn's disease by year of birth and annual notification of measles

Data on the notification of measles are available from 1942, and the UK primary care database (UKPCD) can be used to estimate the age specific prevalence of Crohn's disease. We identified 924553 patients from England and Wales aged 20-55 years (born between 1942 and 1977), of whom 1036 had a diagnosis of Crohn's disease - a prevalence of 11.2 per 10000 . The age specific prevalence for each year shows no obvious association with the pattern of measles epidemics (figure). The highest prevalence of Crohn's disease was in those born between 1949 and 1954. The age specific prevalence since then has been relatively steady and does not support the proposition from Hermon-Taylor et al of a rise in incidence in the disease. ${ }^{2}$ We support Metcalf in her conclusion that there is unlikely to be a causal association between exposure to measles in utero and subsequent Crohn's disease.

Ross Lawrenson Senior lecturer in public health Richard Farmer Professor

Department of Epidemiology and Public Health, Imperial College School of Medicine, London SW10 9NH

1 Metcalf J. Is measles infection associated with Crohn's disease? BMJ 1998;316:166. (17 January.)

2 Hermon-Taylor J, Ford S, Sumar N, Millar D, Doran T, Tizard M. Measles virus and Crohn's disease. Lancet 1995;345:922-3.

\section{Adjuvant radiotherapy is advisable for small invasive breast cancers}

EDitor-Moritz et al have suggested that variations in the management of small invasive breast cancers in the former South East Thames region mean that some patients are denied adjuvant radiotherapy after conservative surgery. ${ }^{1}$ They believe that these patients may be exposed to a greater risk of local recurrence than are the other patients but no reduction in overall survival. The assumption is that local recurrence does not affect long term survival.

They may be underestimating the disadvantage to these patients. Results from the trial by the Danish Cancer Cooperative Group showed that high risk premenopausal women who received adjuvant chemotherapy after surgery had an overall survival at 10 years of $45 \% .^{2}$ The addition of radiotherapy increased the 10 year survival to $54 \%$ ( $\mathrm{P}<0.001)$. Similar results have been shown by Ragaz et al in node positive premenopausal women treated by modified radical mastectomy and chemotherapy. ${ }^{3}$ The addition of radiotherapy produced a $29 \%$ reduction in mortality from breast cancer at 15 years.

If these results are applicable to other patients with breast cancer then local and regional radiotherapy after surgery may confer a general long term survival advantage and should be offered to all patients.

Michael Twitchen Lecturer

Department of Oral Medicine, Guy's and St Thomas's Medical and Dental School, London SE1 9RT

1 Moritz S, Bates T, Henderson SM, Humphreys S, Michell MJ. Variation in management of small invasive breast cancers detected on screening in the former South East Thames region: observational study. BMJ 1997;315:126672. (15 November.)

2 Overgaard M, Hansen PS, Overgaard J, Rose C, Andersson $\mathrm{M}$, Bach F, et al. Postoperative radiotherapy in high-risk premenopausal women with breast cancer who receive adjuvant chemotherapy. N Engl J Med 1997;337:949-55.

3 Ragaz J, Jackson SM, Le N, Plenderleith IH, Spinelli JJ Basco VE, et al. Adjuvant radiotherapy and chemotherapy in node positive premenopausal women with breas cancer. N Engl J Med 1997;337:956-62.

\section{Change in NHS regulations may have caused increase in malaria}

EDITOR-The regulations for prescribing malaria prophylaxis within the NHS were modified in February 1995 to allow general practitioners to charge patients for prescribing these drugs when they were to be used during travel abroad. ${ }^{1}$ It was suggested that the cost to travellers of chemoprophylaxis against malaria might prevent them taking any, or the most appropriate, drug, which could lead to an increase in malaria in Britain. ${ }^{2}$ Another report found that over a third of cases of malaria in Britain occur in immigrants from endemic areas who travel abroad to visit friends and relatives; compliance with chemoprophylaxis among this group of travellers is much poorer than among other travellers. ${ }^{3}$

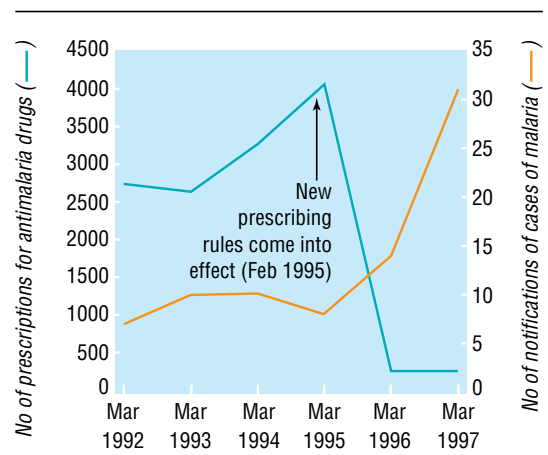

Year

Number of notifications of cases of malaria and number of prescriptions written for malaria prophylaxis in Walsall, 1991-7

We postulated that the new regulations might lead to an increase in the incidence of malaria in areas with ethnic populations who may be economically disadvantaged and also unaware of the availability of chemoprophylaxis. We tested this in our district in Walsall, in which $9 \%$ of the population belong to ethnic minorities.

We compared the number of notifications with the number of prescriptions for malaria prophylaxis written before and after revision of the regulations (as determined by prescribing analyses and cost data from the Prescriptions Pricing Authority). The figure shows the yearly number of prescriptions and malaria notifications for the period from March 1991 to 1997. There was a drop in prescriptions after introduction of the new regulations and an increase in notifications. In a postal survey of all cases notified in 1996, 30 out of 35 responded. All gave a history of overseas travel, and all except one had an Asian surname.

We do not believe that this increase was due to improved notification. Our data on the prescriptions included antimalaria drugs prescribed for all indications: treatment, prophylaxis, and others, such as rheumatoid arthritis. Because the number of cases of malaria is low and antimalaria drugs are seldom used for other indications, the largest part of the prescriptions must have been issued for prophylaxis during travel.

In November 1995 a BBC programme highlighted the possible side effects of mefloquine. This might have contributed to a fall in the number of people taking antimalaria drugs; there was a fall in sales of mefloquine after the programme. ${ }^{4}$

Our data show a sudden increase in malaria in our district, although we cannot infer a causal association. Since the costs of treating malaria greatly exceed the costs of chemoprophylaxis, ${ }^{5}$ it may be necessary to thoroughly review the guidelines on chemoprophylaxis to prevent unnecessary morbidity among travellers and to save money for the NHS.

P Badrinath Specialist registrar in public health O O Ejidokun Specialist registrar in public health N Barnes Pharmaceutical adviser

S Ramaiah Director of public health

Walsall Health Authority, Walsall WS1 1TE ramaiah.s@hsrc.org.uk 
1 Department of Health. Malaria prophylaxis: regulations permitting GPs to charge for prescribing or providing anti-malari drugs. Leeds: NHS Executive, 1995. (FHSL (95)7.)

2 Hollyoak V. Prophylaxis against malaria. BMJ 1995 310:1329.

3 Bradley DJ, Warhurst DC. Guidelines for the prevention of malaria in travellers from the United Kingdom. Commun Dis Rep CDR Rev 1994;7:R 138-52

4 Clift S, Grabowski P. Malaria prophylaxis and the media. Lancet 1996;348:344.

5 Behrens RH, Roberts JA. Is travel prophylaxis worthwhile? Economic appraisal of prophylactic measures against malaria, hepatitis A, and typhoid in travellers. BMJ 1994;309:918-22.

We thank the information division of the Prescription Pricing Authority and the medicines management department at Keele University for providing the prescription data. PACT (prescribing analyses and cost) data are copyright of the Prescription Pricing Authority.

\section{Surgeon never said that excimer laser should no longer be used in refractive surgery}

EDITOR-I wish to correct the quotation about laser treatment to correct short sightedness that was attributed to me in one of the paragraphs in In Brief. ${ }^{1}$ This was taken from a reporting error in the Guardian. ${ }^{2}$ I told my interviewer that at a symposium of the American Society of Cataract and Refractive Surgeons in San Diego on 21 April 1998, attended by 3600 ophthalmologists, I had presented a paper on refractive keratectomy microsurgery. In a personal series of 10000 consecutive cases, only two patients to my knowledge $(0.02 \%)$ had lost two or more lines of visual acuity. By comparison, $12 \%$ of patients had visual loss after surface photorefractive keratectomy by excimer laser for myopia and astigmatism and over $6 \%$ of patients had visual loss after laser in situ keratomileusis. I had taken these figures from a recent paper by Salchow et al in the Journal of Cataract and Refractive Surgery ${ }^{3}$; they are from papers published in the past two years. Recent results of laser in situ keratomileusis report visual loss in 5\% of patients.

This difference in visual safety between refractive keratectomy microsurgery and excimer laser treatment for myopia and astigmatism is large. I told my audience that in view of this it was time to consider whether we would do better to insert silicone lenses behind the pupil and in front of the human crystalline lens to correct refractive errors. At no time have I stated that we should stop using the excimer laser in refractive surgery; many thousands of patients in the United Kingdom are pleased to have had this treatment.

William Jory Ophthalmic consultant

London Centre for Refractive Surgery, London W1N 1PD

William.Jory@lcrs.co.uk

1 In Brief: Surgeon urges end of laser treatment. BMJ 1998;316:1408. (9 May.)

2 Boseley S. Eye surgeon urges end to laser treatment Guardian 29 Apr 1998:11

3 Salchow D, Zirm ME, Stieldorf C, Parisi A. Laser in-situ keratomileusis for myopia and myopic astigmatism. J Cataract Refractive Surg 1998;24:175-82.

\section{Milk intake and bone mineral acquisition in adolescent girls}

Increases in bone density may be result of micronutrients in additional cereal

EDITOR-Cadogan et al reported the effect of increased milk intake on bone mineral acquisition in English schoolgirls. ${ }^{1}$ The results of their study have important implications for childhood dietary policy. We are concerned, however, that the results may be confounded by associated changes in dietary intake. We noted comments made by a participant in the study on a BBC news item that she consumed her additional milk with extra cereal.

Most cereals available in the United Kingdom are supplemented with a variety of vitamins and minerals. Furthermore, there is evidence in the literature that these micronutrients are important to bone health, ${ }^{2}$ and the effect observed may therefore reflect in part the additional micronutrient intake from this source. Indeed, the intake of phosphorus, magnesium, zinc, and vitamins B-1 and B-2 were higher in the milk supplemented group. This may not be solely attributable to the milk.

Details of how the milk was consumed are not given in the paper, but the data should be available from the interim food diaries recording non-weighed food intake over four days that subjects completed on five interim occasions. It would be interesting and important for these additional data to be presented to avoid possible misinterpretation of the results.

Susan New Lecturer in nutrition

Gordon Ferns Professor of metabolic and molecular medicine

Centre for Nutrition and Food Safety, School of Biological Sciences, University of Surrey, Guildford GU2 5XH.

Bryan Starkey Principal biochemist

The Royal Surrey County Hospital, Guildford GU2 5XX

1 Cadogan J, Ealell R, Jones N, Bater ME Milk int bone mineral acquisition in adolescent girls: randomised controlled intervention trial. $B M J$ 1997:315:1255-60. (15 November.)

2 New SA, Bolton-Smith C, Grubb DA, Reid DM. Nutritiona influences on bone mineral density: a cross-sectional stud in pre-menopausal women. Am J Clin Nutr 1997; $65: 1831-9$

Results in two groups are not so different EDITOR-We read with interest the already widely quoted trial by Cadogan et al of the effect of milk supplementation on bone mineralisation in adolescent girls. ${ }^{1}$

From the data presented, we calculate that at the end of the study the mean total bone mineral content was still greater in the control group than the milk group (1845 $\mathrm{g} v$ $1835 \mathrm{~g}$ ), and the mean total bone mineral density was virtually identical in both groups $\left(0.980 \mathrm{~g} / \mathrm{cm}^{2}\right.$ milk $v 0.981 \mathrm{~g} / \mathrm{cm}^{2}$ control).

Could the results not be explained on the basis of a quirk in the randomisation and the fact that the milk treated group were simply biologically "catching up" (or regressing to the mean)?

I D Griffiths Consultant rheumatologist R M Francis Consultant physician
1 Cadogan J, Eastell R, Jones N, Barker M. Milk intake and bone mineral acquisition in adolescent girls: randomised, controlled intervention trial. BMJ 1997;315:1255-60. (15 November.)

2 Today, Radio 4, 14 November 1997.

Adding milk to adolescent diet may not be best means of preventing osteoporosis

EDITOR-Cadogan et al show that supplementing the diets of adolescent girls with dairy milk over 18 months produces a significant increase in bone mineral acquisition. ${ }^{1}$ During the study the intervention group recorded a $52 \%$ increase in mean daily calcium intake, compared with a slight decrease in the control group. The intervention group also recorded a significant increase in mean protein intake from 59.1 to $70.7 \mathrm{~g} /$ day. The authors suggest that this may partly account for their findings.

Other studies, however, have shown that calcium excretion rates increase with increasing protein intake, ${ }^{23}$ generally resulting in negative calcium balance, although this seems to depend on the source of protein. ${ }^{4}$ Thus an increase in protein intake might be expected to limit, rather than enhance, bone mineral acquisition. In suggesting that an increase in milk consumption could make an important contribution to reducing rates of osteoporotic fracture the authors overlook the lessons of ecological studies, which link a diet high in animal protein to an increased incidence of hip fracture in women. ${ }^{5}$

Adding milk to the adolescent diet may be an effective way of increasing calcium intake, but it may not be the best means of preventing osteoporosis in later life. Future studies should compare the effects of different methods of calcium supplementation, including mineral supplements and nondairy sources of calcium, on bone mineral acquisition.

Paul Appleby Research officer

57 Sharland Close, Wantage, Oxfordshire OX12 OAF

1 Cadogan J, Eastell R, Jones N, Barker ME. Milk intake and bone mineral acquisition in adolescent girls: randomised, controlled intervention trial. BMJ 1997;315:1255-60. (15 November.)

2 Allen LH, Oddoye EA, Margen S. Protein-induced hypercalciuria: a long-term study. Am J Clin Nutr 1979;32:741-9. 3 Linkswiler HM, Zemel MB, Hegsted M, Schuette S. Protein-induced hypercalciuria. Fed Proc 1981;40:2429-33. 4 Zemel MB. Calcium utilisation: effect of varying level and source of dietary protein. Am J Clin Nutr 1988;48:880-3.

5 Abelow BJ, Holford TR, Insogna KL. Cross-cultural association between dietary animal protein and hip-fracture: a hypothesis. Calcif Tissue Int 1992;50:14-8.

\section{Authors' reply}

EDITOR-New et al asked whether a change in cereal intake could account for the beneficial effect of a milk supplement in adolescent girls. Cereal consumption at baseline was 3.4\% (median) of dietary energy consumption, and this did not change in either group after 18 months.

We fully appreciate that nutrients other than calcium are essential for bone health and alluded to this in the paper. We performed principal components analysis in an attempt to ascertain the effects of individual nutrient combinations on bone mineral accretion. The models generated for 
increments in total body bone mineral content and total body bone mineral density consistently gave equal weighting to calcium, protein, energy, and phosphorus. No other micronutrients were significant in the model.

Griffiths and Francis commented on the lower total body bone mineral content and total body bone mineral density in the girls randomised to receive milk at baseline and wondered whether the effect we attributed to the milk could have been accounted for by "catch up" growth. If the milk group had less mature skeletons this could have accounted for the difference. The groups did, however, not differ in maturity as assessed by Tanner stage, menarchal status, and oestradiol concentration.

Longitudinal studies of bone density (or any measurement) are subject to statistical artefacts. ${ }^{1}$ Firstly, there may be regression towards the mean. We used analysis of covariance, and the milk effect was still significant after adjusting for baseline bone mass. Secondly, there may be a common variable effect. ${ }^{2}$ To avoid these related problems, we compared the slope of the regression lines of bone mass against time, and these differed significantly (for example, gain per day in bone mineral content was $770 \mathrm{mg}$ /day for milk group and $690 \mathrm{mg} /$ day for controls). We also used the mean of all four time points as denominator when calculating rates of gain, rather than just the baseline measurement of bone mass, as recommended by Oldham. ${ }^{2}$ Thirdly, there may be a "horse racing"effect. This effect was first described for the natural history of chronic bronchitis $^{3}$ and has subsequently been applied to bone density studies. ${ }^{4}$ In our study, this would mean that the girls with the lowest bone mineral content at baseline would have the lowest increment in bone mineral content and so would represent a conservative bias. We believe that the horse racing effect is the most likely source of bias and would have resulted in an underestimate of the effects of the milk supplement.

Richard Eastell Professor in human metabolism and clinical biochemistry

Division of Clinical Sciences, University of Sheffield, Northern General Hospital, Sheffield S5 7AU

Joanna Cadogan Postdoctoral fellow

Department of Food and Nutrition, Purdue University, West Lafayette, IN 47907-1264, USA

Nicola Bright Medical statistician

Trent Cancer Registry, Weston Park Hospital, Sheffield S10 2SJ

Margo E Barker Lecturer in human nutrition Division of Clinical Sciences, University of Sheffield, Northern General Hospital, Sheffield S5 7AU

1 Parfitt AM. Is the rate of bone loss influenced by the initial value? Biological and statistical issues. In: Proceedings of the Perth international bone meeting February 10-13 1995 . Fremantle, Western Australia. Perth: Wilson and Price, 1995:69

2 Oldham PD. Measurement in Medicine: the interpretation of numerical data. London: English Universities Press, 1968 148-52.

3 Fletcher CM. The natural history of chronic bronchitis Community Health 1975;7(2):70-8.

4 Van Hemert AM, Vandenbroucke JP, Hofman A Valkenburg HA. Metacarpal bone loss in middle-aged women: "horse racing" in a 9-year population based follow-up study. J Clin Epidemiol 1990;43:579-88.

\section{Pay rates for junior doctors' additional hours need to be adjusted}

EDITOR-Work out of hours (additional duty hours) performed by junior doctors working on call rotas is currently paid at $50 \%$ of the standard hourly rate. Many junior doctors find this rate insulting and think that overtime, being compulsory and demanded by a monopoly employer, should be just what it says.

Pay rates should therefore be at least the same as for a normal working day, for reasons of responsibility, inconvenience, and comparability with pay for work done outside normal working hours in other professions and trades. The annual evidence given by the BMA's Junior Doctors Committee to the pay review body for doctors and dentists has stated this for many years; yet since 1991, when the new deal was agreed, ${ }^{1}$ there have been no further increases in rates for additional duty hours since the increase from $38 \%$ to $50 \%$. Our fellow health professionals who share our commitment out of hours to the NHS have long been amazed that such a pay rate exists. Many do not believe us.

We have surveyed nurses, patients, and medical students from two different years and assessed each group's knowledge of the current pay rates for junior doctors. Ethical approval for the study was obtained. The participants were handed a brief questionnaire asking their age and sex and how much they thought a preregistration house officer would be paid per hour on Christmas Day 1997, given that they would be earning $£ 7.42$ per hour on Christmas Eve, a normal working day. The participants' responses were collected directly thereafter. We obtained 529 replies, of which 523 answered the question on out of hours pay ( 86 patients, 157 nurses, 168 first year and 118 fourth year medical students; mean (SD) age 29.2 (15.1) years).

The figure shows the frequency of replies. One way analysis of variance indicated pairing of the groups, with first year medical students and patients (means $£ 12.34$, £13.73 respectively) estimating significantly higher than nurses and fourth year students $(£ 9.37, £ 9.80) \quad(\mathrm{P}<0.001)$.

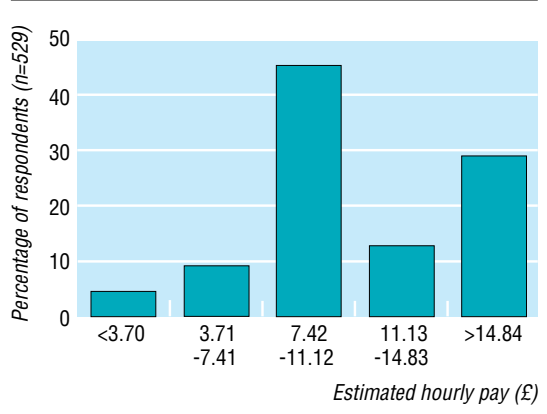

Distribution of estimated hourly pay for additional duty hours of junior doctors by nurses, patients, and medical students
There was no correlation between the estimate given and either age or sex overall or within any of the groups.

To our knowledge this is the first study to examine this issue. Only 14 respondents correctly estimated the hourly pay rate at $£ 3.71$. Most (510) estimated a pay rate of at least $100 \%$, and a significant minority (155) estimated that preregistration house officers were paid at "double time" or more. If patients, medical students, and nurses believe that junior doctors are paid at these sorts of rates, we believe that this is cogent evidence of public opinion that they should.

Trevor Pickersgill Research fellow in neurology H G Kynaston Consultant urologist

University Hospital of Wales Healthcare NHS Trust and University of Wales College of Medicine, Cardiff CF4 4XW

Rhidian Hurle Senior house officer in orthopaedics and trauma

Glan Hafren NHS Trust Royal Gwent Hospital, Newport, Gwent NP9 2UB

Gary Small Senior house officer in oncology Velindre NHS Trust, Cardiff CF4 7XI

TP, RH, and GS are junior doctors. RH and TP are members of the Junior Doctors Committee of the BMA.

1 NHS Management Executive. Junior doctors-the new deal. London: Department of Health, 1991.

\section{Resuscitation}

\section{Trainees' adverse experiences of the new} recovery position

EDitor-In reply to the request by the Resuscitation Council UK ${ }^{1}$ to report experiences regarding the recovery position of the 1997 International Liaison Committee On Resuscitation (ILCOR 97), ${ }^{2}$ research carried out by a team in Cardiff has shown a number of important issues that need to be addressed.

A comparison between the positions of the European Resuscitation Council 1992 (ERC 92) $^{3}$ and ILCOR 97, in which 86 members of the community participated, has shown a marked preference for the ERC 92 recovery position. A self administered questionnaire was developed to elicit quantitative and qualitative information from adults attending emergency life support courses taught by Heartstart Cardiff and the Vale Instructors. The questionnaire used a Likert scale and gave open and closed questions.

Two questions asked for the rescuer's opinion when comparing the techniques of the ERC 92 and ILCOR 97 recovery positions. The rescuer's opinion was recorded using a Likert scale of "easy" to "difficult." A closed question then asked which technique the rescuer would use if he or she had a free choice. Three open questions then asked the trainee and the "casualty" for comments on the near side arm position, the turn, and the final resting position.

The table shows that trainees in the role of the rescuer were more likely to report that the 1992 position was very easy and trainees 
Opinions of 86 trainees about the recovery position of the 1992 European Resuscitation Council and the 1997 International Liaison Committee on Resuscitation

\begin{tabular}{ccc} 
& 1992 & 1997 \\
European & $\begin{array}{c}\text { International } \\
\text { Liaison } \\
\text { Resuscitation } \\
\text { Council }\end{array}$ & $\begin{array}{c}\text { Committee on } \\
\text { Resuscitation }\end{array}$ \\
\hline
\end{tabular}

\begin{tabular}{lcc}
\hline Rescuer role & & \\
\hline Very easy & 81 & 6 \\
\hline Fairly easy & 4 & 32 \\
\hline Fairly difficult & 0 & 26 \\
\hline Very difficult & 0 & 22 \\
\hline Void & 1 & 0
\end{tabular}

Casualty role

\begin{tabular}{ll}
\hline Near side arm: & \\
\hline Positive & 73
\end{tabular}

\begin{tabular}{lrr}
\hline Positive & 73 & 9 \\
\hline Negative & 3 & 66 \\
\hline No comments/similar & 10 & 11 \\
\hline
\end{tabular}

The turn:

\begin{tabular}{lrr}
\hline Positive & 80 & 4 \\
\hline Negative & 0 & 72 \\
\hline No comments/similar & 6 & 10 \\
\hline
\end{tabular}

\begin{tabular}{lrl} 
No comments/similar & 6 & 10 \\
\hline Final position: & & \\
\hline Positive & 72 & 17 \\
\hline Negative & 6 & 56 \\
\hline No comments/similar & 9 & 13 \\
\hline
\end{tabular}

in the role of the casualty were more likely to report positively on the near side arm position, the turning process, and the final position (all $\mathrm{P}<0.001$ ).

The following are examples typical of qualitative comments made by trainees: "This hurts!! it felt like my arm was breaking." (ILCOR 97) "I definitely prefer ERC 92, ILCOR 97 was damn painful." "I strongly recommend my lifeguard team not to use ILCOR 97 as it is uncomfortable for the casualty."

In view of these results from community resuscitation training we feel that a return to the original ERC 92 recovery position should be considered. Ambulance response times to emergency calls in the United Kingdom mean that a casualty need rarely be kept in the recovery position for more than 10 minutes, so ease of training and avoidance of discomfort for trainees need to be balanced against minimising the risk to the casualty over this short time span. ${ }^{4}$

Steve Leaves Resuscitation training officer Peter Donnelly Honorary senior lecturer

Carolyn Lester Research fellow

David Assar Associate director

University of Wales College of Medicine, Centre for Applied Public Health Medicine, Temple of Peace and Health, Cardiff CF1 3NW

1 Handley AJ. Resuscitation Council (UK) wants everyone who uses the new recovery position to report experiences. BMJ 1997;315:1308. (15 November)

2 Handley AJ, Becker LB, Allen M, van Dreuth A, Kramer EB, Montgomery WH. Single rescuer adult basic life support: an advisory statement from the basic life support working group of the International Liaison Committee on Resuscitation (ILCOR). Resuscitation 1997;34:101-8.

3 Basic Life Support Working Party of the European Resuscitation Council. Guidelines for basic life support: a statement. Resuscitation 1992;24:103-10.

4 Fulstow R, Smith GB. The new recovery position, a cautionary tale. Resuscitation 1993;26:89-91
Some aspects of 1997 guidelines are less helpful than old guidelines

EDITOR-As a junior house officer I found the pocket version of the 1992 European Resuscitation Council algorithm an extremely useful tool for learning and remembering advanced life support.

The UK Resuscitation Council has adopted the 1997 guidelines based on the advisory statements of the International Liaison Committee on Resuscitation. ${ }^{1}$ These are the result of a five year review of the evidence and an attempt to achieve international standardisation. The algorithm is designed to improve ease of training and memory retention. ${ }^{2}$

Two improvements are the simplification of the algorithm into ventricular fibrillation/ventricular tachycardia or nonventricular fibrillation/ventricular tachycardia and the four $\mathrm{Hs}$ plus four Ts of potentially reversible causes. Unfortunately, other aspects are less helpful than the 1992 algorithm for the following reasons.

(1) There are no stated energy requirements for defibrillation.

(2) No dose of epinephrine is given.

(3) It is not yet universally appreciated that epinephrine is adrenaline.

Hopefully the Resuscitation Council will consider these points in time for the 1998 European Resuscitation Council guidelines that are to be announced in Copenhagen next month.

Arun Sharma Senior house officer

Raigmore Hospital, Inverness IV2 3UJ

1 Kloeck W, Cummins R, Chamberlain D, Bossaert L, Callanan V, Carli P, et al. The universal ALS algorithm. Resuscitation 1997;34;109-11.

2 Donnelly P, Chamberlain D, Handley A, Assar D, Lester C. New advisory statements on life support have been published. $B M J$ 1997;315;1308. (15 November.)

\section{Resurgence of interest in medical oaths and codes of conduct}

\section{A universal code of conduct is difficult to develop}

EDITOR-By missing out the first line of the Hippocratic Code, Hurwitz and Richardson have altered the meaning, ${ }^{1}$ which begins: "I swear by Apollo the physician, by Aesculapius, Hygeia and Panacea, and I take to witness all the gods, all the goddesses, to keep according to my ability and judgement the following oath." Clearly, 2500 years ago the Greeks thought that judgment of success was divine as well as secular.

In developing a universal code there is the problem of: "How to develop an all embracing ethical code of practice if one makes the code relative to local circumstances?" 1 The draft revision of the Hippocratic Oath states: "Where abortion is permitted, I agree that it should take place only within an ethical and legal framework." Will the Dutch Medical Association want to include euthanasia?
The Gordian knot concerns the relation between morals based on ideas of community, values, and the worth of individuals, and the law based on encoded practice.

When moral values are in disagreement with the law of the land, conflict ensues. The Hippocratic Oath was based upon a Pythagorean concept of respect for life. After the Nuremberg trials, the Geneva Convention included the line: "I will maintain the utmost respect for human life from its beginning, even under threat, and I will not use my specialist knowledge contrary to the laws of humanity; I make these promises solemnly, freely, and upon my honour." By making the gift of life a material choice the medical profession opened Pandora's box.

Myself and a colleague recently reported on a three year study of the practical problems doctors and nurses face about decision making at the end of a patient's life. ${ }^{2}$ The participants were confused about questions such as "Who is responsible for death when treatment is withdrawn?" and "Why is it not necessary always to treat?" To overcome this confusion we proposed three moral principles that should govern clinical practice: (a) Treatment of patients must reflect the inherent dignity of every person irrespective of age, debility, dependence, race, colour, or creed; (b) Actions must reflect the needs of the patient where he or she is; and (c) Decisions taken must value the person and accept human mortality.

These principles put clinical judgment into an ethical concept of tending. The tending that patients receive will be limited by the doctor's skills, the expert opinion available to him or her, and resources, but it will always be patient centred.

In constructing a new set of values to take note of modern times the taskforce could begin by adopting these values as the basis for decision making at the end of life.

Peter H Millard Eleanor Peel professor of geriatric medicine

Division of Geriatric Medicine, St George's Hospital School of Medicine, London SW17 0RE

1 Hurwitz B, Richardson R. Swearing to care: the resurgence in medical oaths. BMJ 1997;315:1671-4. (20-27 December.) 2 Jeffery P, Millard PH. An ethical framework for clinical decision-making at the end of life. $J R$ Soc Med 1997:90:504-6.

\section{Killing can never be morally acceptable}

EDITOR-It is timely to consider Hippocrates and his oath and the draft revision of the Hippocratic Oath, particularly in relation to killing and abortion since intrauterine destruction is now commonplace and legal under many conditions. ${ }^{1}$

In the original Hippocratic Oath the precept on killing was: "I will not give a fatal draught to anyone if I am asked; nor will I suggest any such thing. Neither will I give a woman means to procure an abortion." The draft revision of the oath states: "Where abortion is permitted I agree that it should take place only within an ethical and legal framework." No ethical or legal framework can contradict the natural law enshrined in the Ten Commandments. 
The commandment "Thou shalt not kill" is an imperative, repeated in the Hippocratic Oath, which cannot be disobeyed without a gross act of injustice being done, whether to the unborn child or any other human. Killing, carried out by the medical profession or others, can never be made morally acceptable by an act of parliament or a revised oath.

The draft revision of the Hippocratic Oath also includes the statement: "I will make every effort to ensure that the rights of all patients are respected, including vulnerable groups who lack the means of making their needs known ...." This must apply with special force to unborn infants and debilitated and elderly people.

The words of one author are worth recalling: "Though I had been in medicine for 30 years, I realised for the first time at the Nuremberg trials the full meaning of the contributions of Hippocrates and his school, to medicine and human welfare."

John Scotson General practitioner

5 Woodville Road, Altrincham, Cheshire WA14 2AN

1 Hurwitz B, Richardson R. Swearing to care: the resurgence in medical oaths. BMJ 1997;315:1671-4. (20-27 December.) 2 Ivy AC. Nazi war crimes of a medical nature. JAMA 1949;139:133

\section{Solemn promise is not kept by some doctors}

EDITOR-Working in both the NHS and private practice inevitably produces a conflict of interest for doctors. It is well known by the public that the waiting time for treatment can be reduced by paying the consultant

In the draft revision of the Hippocratic Oath the doctor makes "a solemn promise not to put personal profit above his duty to patients." It seems that doctors who combine private practice with NHS practice often have difficulty keeping this solemn promise

J W B Forshaw Retired consultant physician

12 Baroncroft Road, Woolton, Liverpool L25 6EH

1 Hurwitz B, Richardson R. Swearing to care: the resurgence in medical oaths. BMJ 1997;315:1671-4. (20-27 December.)

\section{Colour deficient vision should not prevent a career in histopathology}

EDITOR-Poole et al report that histopathologists with colour deficient vision make more errors in the identification of slides stained by colour dependent methods, such as Ziehl-Neelsen, than those with normal colour vision. ${ }^{1}$ However, the authors do not indicate how many of the 15 histopathologists with colour deficient vision were already aware of their limitations, whether "don't know" was accepted as an answer in the slide identification study, and if so whether this was reported as an error.

I am a histopathologist with severe red-green colour deficiency; I have never found it to be more than a minor inconvenience, since a moment's help from a colleague with normal colour vision solved any difficulty I might have had with colours in histological preparations.

I have no objection to colour vision being tested as part of the routine preemployment examination of all medical staff. My concern is that the selective testing of prospective histopathologists might lead occupational health staff, or others with little knowledge of histopathology, to think that colour deficient vision is a serious handicap to a career in the specialty. That this is far from the case is suggested by the fact that not too long ago the two professors of pathology (histopathology) at Glasgow University and the professor of dermatology, a distinguished skin histopathologist, were al colour blind.

Robert B Goudie Emeritus professor of pathology, University of Glasgow

19 Dumgoyne Drive, Bearsden, Glasgow G61 2AP

1 Poole CJM, Hill DJ, Christie JL, Birch J. Deficient colou vision and interpretation of histopathology slides: cros sectional study. BMJ 1997;315:1279-81. (15 November.)

\section{Single assessment of risk predicted which elderly patients would fall}

EDITOR-Oliver et al used a scientific approach to develop an evidence based risk assessment tool that predicts with high specificity which elderly inpatients will fall. ${ }^{1}$ Between July and September 1996 we examined risk factors prospectively for 154 patients admitted to two acute and rehabilitation geriatric wards in a district general hospital. Our aim was to identify factors on admission that might have predictive value for the duration of the inpatient episode. A simple risk assessment form for falls was completed once by the admitting nurse. ${ }^{2}$

We recorded 53 falls by 29 patients. There was no association between a fall and the following observations: agitation, temporal or spatial disorientation, toileting difficulties, and mobility not requiring supervision. For several factors the difference in distribution between fallers and non-fallers seemed unlikely to have occurred by chance. These factors included a medical history of broken hip, stroke, or Parkinson's disease; history of a fall within the past month; supervision needed for all mobility; and poor eyesight (all $\mathrm{P}<0.05$ ).

We then considered that having more than two of these associated factors indicated a high risk of falling. In the lower risk group the probability of falling was 1 in 7 , and in the higher risk group it was 1 in 2, a risk ratio of $3.31(95 \%$ confidence interval 1.8 to 6.1$)$. Calculations of specificity and sensitivity were $89.6 \%$ and $38 \%$ respectively (table).

In contrast to Oliver et al, we chose to examine factors that were present just on admission rather than assess the patients at weekly intervals. Elderly patients can undergo rapid changes in orientation and mobility after acute admission; we found that the factors with a predictive value for
Number of risk factors noted for 154 patients admitted to geriatric wards who did and did not fall during their stay in hospital

\begin{tabular}{lrrr} 
No of risk factors & Faller & Non-faller & Total \\
\hline 3 or 4 ("at risk") & 11 & 13 & 24 \\
\hline 0 to 2 ("no risk") & 18 & 112 & 130 \\
\hline All patients & 29 & 125 & 154 \\
\hline
\end{tabular}

the duration of the patients' stay were purely historical and unlikely to change quickly. Oliver et al's repeated assessments allowed the impact of more changeable predictors to be registered.

In the population in a district general hospital Oliver et al found that if specificity of $87.6 \%$ was achieved, sensitivity dropped to $54.4 \%(42.8 \%$ to $65.7 \%)$. This raises the issue of whether repeated assessments in this population are worth while, as these figures are similar to our own. Ultimately the type of assessment needed will reflect the ward population, as a longer stay rehabilitation ward may be just as well served by a single assessment of risk based on more stable factors, whereas an acute ward would need a repeated review of predictors that can change more rapidly.

Christopher Price Research fellow academic department

Michael Suddes Practice development nurse, academic department

Linda Maguire Falls nurse specialist, academic department

Sam Harrison Audit facilitator, academic department Diarmuid O'Shea Consultant physician, department of medicine

North Tyneside General Hospital, North Shields NE29 8NH

1 Oliver D, Britton M, Seed P, Martin FC, Hopper AH. Development and evaluation of evidence based risk assessment tool (STRATIFY) to predict which elderly inpatients will fall: case-control and cohort studies. BMJ 1997;315:1049-53. (25 October.)

2 Price C, Suddes M, O'Shea D. Predicting ward falls: validation of a quick nurse-led assessment of falls risk. Age Aging (in press).

\section{The "Diana effect"}

\section{Hospital experienced a decrease in} number of admissions for trauma

EDIToR-The death of Diana, Princess of Wales has been followed by an unprecedented public and media response. Shevlin et al showed that her death and subsequent funeral have had a profound psychological impact on the public. ${ }^{1}$ Furthermore, many people have consulted their general practitioners for depression linked to the princess's death. $^{2}$

It is therefore perhaps surprising that in contrast to the increased number of consultations for psychological problems the number of admissions for trauma at the North Staffordshire Royal Infirmary has fallen by $10 \%$ since Diana's death. Perhaps more poignantly (figure) the number of admissions of patients with injuries greater than 15 on the injury severity score has fallen. This trend continued for three months; only in December did numbers start to return to previous values. Most of the 


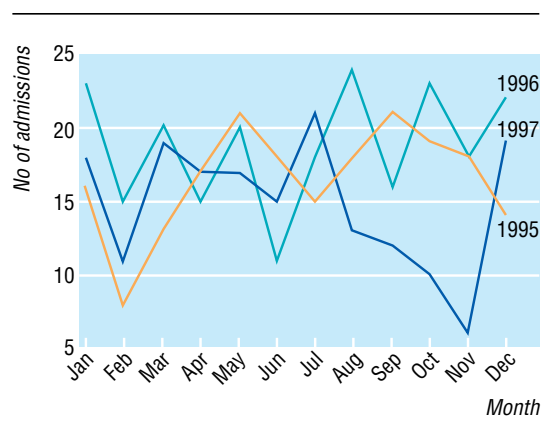

Numbers of admissions for trauma (injury severity score $>15)$, 1995-7

patients are injured in road traffic accidents, and it would be tempting to imply a causalalbeit probably subliminal-association with driving habits after the tragic events in Paris.

It is too soon to judge whether the tragic manner of Princess Diana's death will have a lasting impact on admissions for trauma, but we would be interested to know whether other centres have experienced a similar fall in the number of acute and severely injured patients.

Rhidian Morgan-Jones Senior orthopaedic registrar Kevin Smith Senior orthopaedic registrar

Peter Oakley Consultant anaesthetist

1 Shevlin M, Brundsen V, Walker S, Davies M, Ramkalawan T. Death of Diana, Princess of Wales. BMJ 1997;315:1467. (29 November.)

2 Morris B. GPs called into action to help nation recover from shock of Diana's death. BMA News Review 1997 Sep 24:18.

\section{Number of inappropriate hospital admissions increased}

EDITOR-Further to the letters by Williams et al and Shevlin et al on the effects of the death of Diana, Princess of Wales ${ }^{12}$ we have made an observation regarding acute hospital admissions. Many general practitioners know that a reduction in demand for admissions at times of significant events, holidays, and so on, is often rapidly followed by an escalation of demand. There is little in the literature about this well recognised phenomenon.

We conducted a study of acute hospital admissions in Belfast. We used the appropriateness evaluation protocol, ${ }^{3}$ which characterises validly and reliably whether acute admissions are appropriate (whether patients show clinical signs that demand admission) or inappropriate. We used a version that has been modified for use in the NHS. ${ }^{4}$ Studies across Europe using the protocol have indicated that inappropriate admissions constitute some $20-25 \%$ of total admissions.

Our most recent prospective study was conducted during September 1997 and was in progress at the time of the death of Princess Diana (31 August 1997).

The figure shows the rate of inappropriate admissions during the course of our study. It shows a centred moving average rate of inappropriate admissions on the basis of the last 50 admissions and is updated every time a new admission is made. The average rate of inappropriate admissions was $19 \%$. Immediately before the funeral the number of inappropriate admissions fell to a very low rate. On the weekend of the funeral (6 September 1997), inappropriate admissions fell significantly to almost none $\left(\chi^{2}=24.76, \mathrm{df}+3 ; \mathrm{P}<0.001\right)$.

In the days after the funeral the moving average rate of inappropriate admissions rose rapidly to a rate that was significantly higher than average. Between 10 September and 15 September the rate of inappropriate admissions was $50 \%$ above the average for the whole month. No other peaks or troughs in the figure were shown to be statistically significant. This shows that the degree of trauma was so great at this event that people delayed seeking advice, and their own problems took on a secondary importance. This delay only lasted during the extensive media coverage, and after the weekend of the funeral there was an increase in the number of inappropriate admissions.

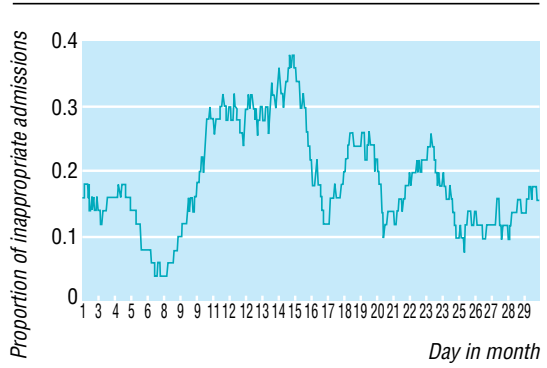

Centred moving average (50) of proportion of inappropriate admissions during September 1997

The level of appropriate admissions did not fall during this time. This shows, as we already suspected, that hospital is not really necessary for a significant proportion of acute admissions that could be managed by alternative means and for which a delay of perhaps a day or more would not be detrimental to the patient.

Carolyn Berry Research fellow

Clive Mulholland Lecturer

Michael Stevenson Consultant statistician

Philip Reilly Professor of general practice

Department of General Practice, the Queen's

University, Belfast BT9 7HR

1 Williams ERL, Meadows J, Catalan J. Death of Diana Princess of Wales. BMJ 1997;315:1467. (29 November.)

2 Shevlin M, Brunsden V, Walker S, Davies M, Ramkalawa T. Death of Diana, Princess of Wales. BMJ 1997;315:1467. (29 November.)

3 Gertmann PM, Restuccia J. The appropriateness evaluation protocol: a technique for assessing unnecessary days in hospital care. Med Care 1981;19:8.

4 Bristow A, Hudson M, Beech R. Analysing acute inpatient services: the development and application of utilisation reviou tools. London: Department of Public Health Medicine, United Medical and Dental Schools of Guy's and St Thomas's Hospitals, 1997.

There was no "Diana effect" on numbers of psychiatric emergencies

EDiToR-The death of Diana, Princess of Wales on 31 August 1997 and her funeral on 6 September were associated with a $30 \%$ reduction in calls to the police and a $28 \%$ drop in public order offences during the week of informal public mourning. ${ }^{1}$ The
Samaritans reported an increase in the amounts of calls after the death. ${ }^{1}$ There have also been reports of increased depression ${ }^{2}$ and traumatic stress. ${ }^{3}$

The death and funeral might have affected psychiatric emergency presentations including parasuicide. The ensuing public distress might have increased the use of emergency psychiatric services, or the "outpouring of fellowship," as described in the Guardian, ${ }^{1}$ might have reduced the use of these services, distracting people from their own personal problems.

All people admitted for parasuicide to Edinburgh Royal Infirmary are assessed. People can present as psychiatric emergencies or be referred to the accident and emergency department at the infirmary or at the psychiatric hospital at the Royal Edinburgh Hospital. I studied cases presenting to these services, comparing those presenting in the two weeks in which the death and the funeral occurred (31 August to 13 September) with those presenting in the two weeks before (17 August to 30 August). There were 238 contacts with 126 cases of parasuicide in the two weeks of the death and funeral and a total of 269 contacts including 136 parasuicides in the two weeks before $(\mathrm{P}<0.1$ in two tailed $t$ test). There was no obvious change in the numbers of presentations or cases of parasuicide on the day after the death or the funeral. Thus there seemed to be no "Diana effect" on the numbers of psychiatric emergencies and parasuicides in Edinburgh.

John R Mitchell Senior registrar in psychiatry Affleck Centre, Royal Edinburgh Hospital, Edinburgh EH10 5HF

1 Diana's death cut crime as nation mourned together. Guardian 1997 Oct 17:4

2 Morris B. GPs called into action to help nation recover from shock of Diana's death. BMA News Review 1997 Sep 24:18.

3 Shevlin M, Brunsden V, Walker S, Davies M, Ramkalawan T. Death of Diana, Princess of Wales. BMJ 1997;315:1467. (29 November.)

\section{Advice to authors}

We prefer to receive all responses electronically, sent either directly to our website or to the editorial office as email or on a disk. Processing your letter will be delayed unless it arrives in an electronic form.

We are now posting all direct submissions to our website within 72 hours of receipt and our intention is to post all other electronic submissions there as well. All responses will be eligible for publication in the paper journal.

Responses should be under 400 words and relate to articles published in the preceding month. They should include $\leqslant 5$ references, in the Vancouver style, including one to the BMJ article to which they relate. We welcome illustrations.

Please supply each author's current appointment and full address, and a phone or fax number or email address for the corresponding author. We ask authors to declare any conflicts of interest.

Letters will be edited and may be shortened.

www.bmj.com

letters@bmj.com 